\title{
Challenges for prison governors and staff in implementing the Healthy Prisons
}

Agenda in English prisons.

Objectives: In the two decades that have passed since the World Health Organisation established the Healthy Prisons Agenda, there has been no research conducted to investigate barriers and challenges prison managerial and operational staff encounter in implementing the Agenda in the English prison context. This paper debates sectoral, institutional, and occupational challenges perceived to hinder effective implementation of the Agenda, based on a qualitative study involving prison governors and operational staff.

Study design: Qualitative study taking a grounded theory approach.

Methods: Semi-structured interviews were conducted with 30 participants comprising prison governors, prison officers and external stakeholders with key strategic and operational roles across the prison estate. The interviews were analysed and coded into themes using constant comparative method.

Results: The research identified a range of managerial and operational factors that impeded recognition, acceptance and successful implementation of the Healthy Prisons Agenda. These were found to be associated with scarcity of resources, low prioritisation, perceived low importance, and pressures at operational, managerial and strategic levels to adhere to standard operating procedures. Security, control and discipline tended to supersede other imperatives considered of secondary importance to the effective running of prisons.

Conclusions: Sustainability of the Healthy Prisons Agenda can only be assured by raising its significance and importance across prison hierarchies and within policies and practices through which operational and strategic objectives are realised. This means achieving wholesale commitment by prisons-among staff at all levels-towards public health goals, which are fundamental to a successful and effective criminal justice system.

Keywords: Healthy Prisons Agenda, prison health, prisoner health, prison governors, prison officers, healthy setting. 


\section{Introduction}

It is widely acknowledged that prison populations in all countries of the world, England being no exception, carry a disproportionately high burden of communicable and noncommunicable disease, ill-health and disability. ${ }^{1-3}$ It is moreover the case that the most socio-economically disadvantaged communities, where levels of social exclusion, disadvantage and inequality are most marked, are significantly overrepresented within prison populations. ${ }^{4}$ It is not surprising, therefore, that prisons accommodate large numbers of people with complex health and social needs, many exhibiting high risk health behaviours. It is in this regard that the World Health Organisation (WHO) introduced the Healthy Prisons approach in 1995 as a system-wide strategy for protecting and improving the health of prisoners. ${ }^{5}$ Building upon the definition of health as "a state of complete physical, mental, and social well-being, and not merely the absence of disease or infirmity", 6 its principal objectives were to address prisoners' health needs and risks, to recognise and mitigate against the harmful health impacts of imprisonment and, consistent with these objectives, to safeguard prisoners' human rights and access to health services comparable (or 'equivalent') to those available to the general population. The Healthy Prisons ethos is derived from WHO's 'healthy settings' strategy for health promotion, which is holistic and multidisciplinary, and emphasises participation, partnership, empowerment and equity. ${ }^{5}$ For prisons, this means adopting a system-wide public health strategy, embedding health within the core business of the system, and addressing health impacts of imprisonment and inequalities, necessary for effective and sustainable offender management and rehabilitation. ${ }^{7}$ These aspirations are recognised and audited by $\mathrm{HM}$ Inspectorate of Prisons through assessment of institutions' fitness as safe, secure, reforming and health-promoting environments, and of their success in embracing decency and safeguarding human rights. ${ }^{8}$

The Healthy Prisons Agenda advocates the "whole-prison approach", a philosophy that prioritises the health of prisoners as well as that of the prison staff members, and promotes an environment conducive for health to thrive. ${ }^{5}$ Reinforced by supportive policies and initiatives, the Agenda seeks to invert Goffman's traditional portrayal of prisons as institutions where strict regimes, hierarchical relationships, and enduring bureaucracies are normalised as part of prisons' environment and culture, ${ }^{9}$ but which 
can be detrimental to health. Additionally, the Agenda attempts to move away from a biomedical perspective to a more holistic and social model of health, providing thus an opportunity to address health inequalities of the hard-to-reach groups all under one roof-those who frequently fall through the National Health Service (NHS) safety net. ${ }^{7}$ Recently, these realisations have been further strengthened through the National Partnership Agreement for Prison Healthcare in England 2018-2021-concluded between the Ministry of Justice, Her Majesty's Prison and Probation Service (HMPPS), Public Health England, the Department of Health and Social Care, and NHS Englandthat promotes collaboration on improving health outcomes for prisoners and reducing health inequalities of prisoners, addressing health-related drivers of their offending behaviour, and improving continuity of care across the criminal justice pathways. ${ }^{10}$

The ability of prisons to effectively operationalise the Healthy Prisons Agenda has been significantly reduced through year-on-year reductions in prison funding and resourcing by the UK Government, which, we would argue, brings consequences for prisoner health. During the period 2009-2017, the UK Government reduced operational funding for the HMPPS by $13 \%$, which led to a $30 \%$ reduction in prison staff. ${ }^{11}$ During this period, the prison population has continued to grow (Figure 1). ${ }^{12}$ Operational and managerial staff experience high levels of stress and burnout, high sickness levels, high turnover, and early retirement. ${ }^{13}$ The Prison Service faces a recruitment crisis emanating from relatively low and static salaries and unfavourable employment terms and conditions, which makes it difficult to attract a high quality and experienced workforce. ${ }^{13}$ This inevitably impacts both the quality and duty of care prisons have for prisoners, across the range of health, social, educational and employability needs of prisoners, most of whom will be released back to society. 


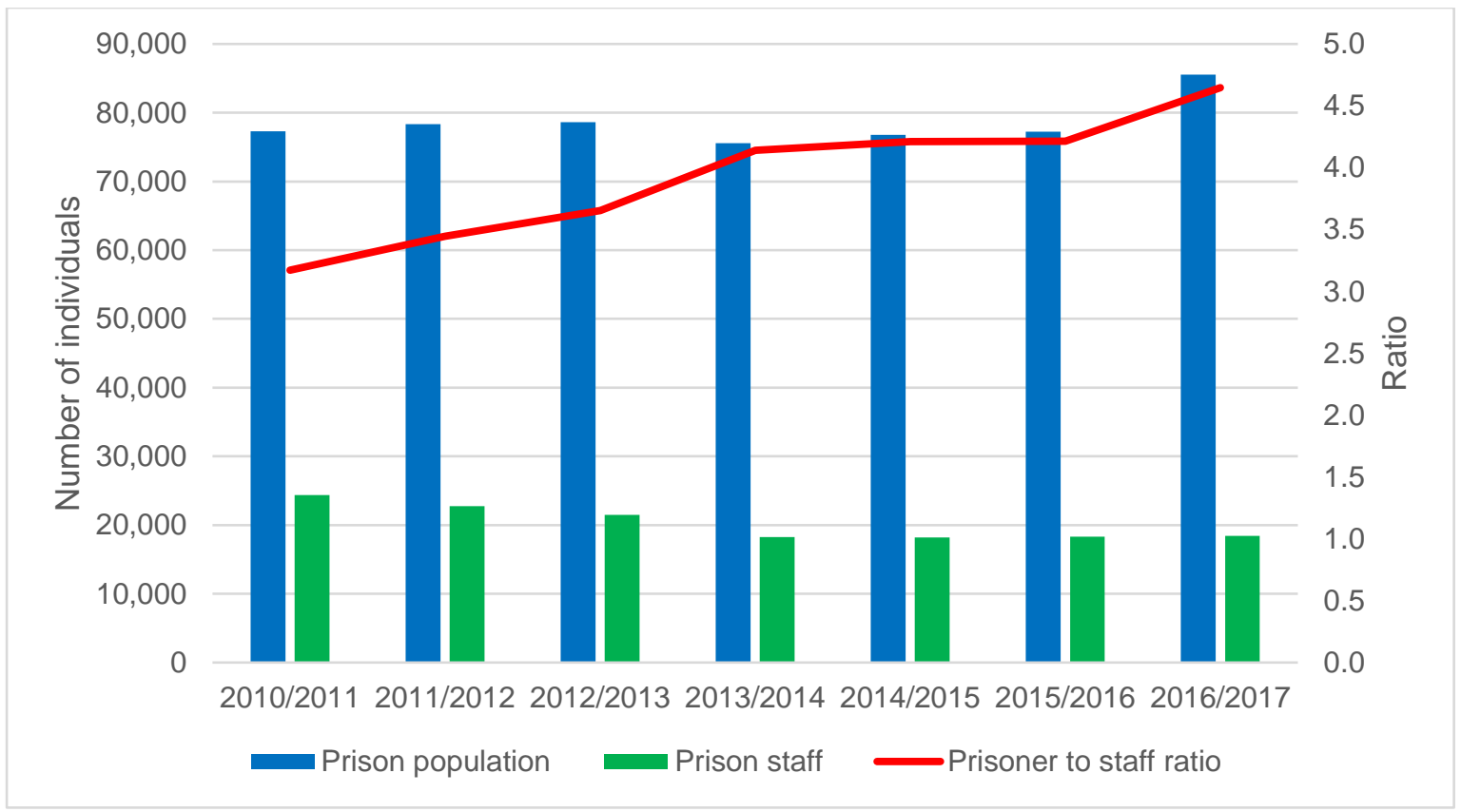

Fig 1. Number of core prison staff and prison population in England and Wales, 2010/2011 to 2016/2017

Multifaceted factors of institutional, environmental, and personal are determinants of the rehabilitative culture within detention. Considering that health is not solely dependent upon healthcare services, different parts of the prison system should work collaboratively to address the colossal health and social care issues experienced by prisoners. Routine and continual interactions between prison staff and prisoners can engender such a culture. ${ }^{14}$ Nevertheless, available research suggests that, in prisoner-staff relationships, prison officers tend to exert this discretion by focusing on punishment and control, rather than on care and empathy. ${ }^{13,15}$ Several studies have related this detrimental lack of empathy to the focus, in prison officers' training, on security and institutional order. ${ }^{16}$ Under this training system, training in assisting prisoners with complex needs has been deemed inadequate, with prison officers typically perceiving health activities to be outside of their professional remit. ${ }^{17}$ This is in spite of the duty of care that the prison officials have to protect prisoners from injury and harm, as reinforced by Article 2 of the European Convention on Human Rights, which imposes a positive obligation to take preventative operational measures to protect an individual whose life is at risk. 
Institutional culture is an important area where change is necessary, although this has to happen alongside significant increases in prison resources, especially in terms of staffing and workforce development. Prison governors and area managers have a key role to play, given their power to steer and motivate their workforces, and their location often at the centre of a multidisciplinary workforce given ever increasing involvement of voluntary, community and private sector organisations in delivering prison services. ${ }^{18}$ This requires skill and diplomacy to facilitate and balance competing priorities, where distinct professional value positions prevail. Such an intersectoral context will inevitably bring conflict of interest between different professional groups, which will be particularly heightened where prison governors and managers, on account of scarce resources, are preoccupied with safety and control, which can work towards the detriment or health and welfare. ${ }^{19}$ Prison governors are moreover instructed by central government to embrace regulations and instructions that can be vague and conflicting, which means that, pragmatism often takes precedence. ${ }^{20}$

To date, no previous research has explored the barriers and challenges prison managerial and operational staff encounter in implementing the Healthy Prisons Agenda within the English prison context. This paper reports on a study that used qualitative interviews to understand sectoral, institutional, and occupational factors.

\section{Methods}

The findings discussed in this paper contributed to a larger qualitative study investigating the potential value of introducing legislation to implement the Healthy Prisons Agenda in England. Given the absence of knowledge in this area, an inductive grounded theory approach was considered appropriate to enable exploration of the issues and thereby develop new insight and theory from the emerging qualitative data. ${ }^{21}$

Semi-structured interviews were conducted with 30 key informants who were considered to have experience with delivering the Healthy Prisons Agenda at both the strategic and operational levels in prisons in England. Participants included internal informants - people employed directly by prisons, both governors and officers $(n=13)$ - and external informants - people employed in health care-delivering organisations 
who provide or oversee care in prison $(n=17)$. Participants were recruited using a combination of purposive, theoretical, and snowball methods. ${ }^{22}$ Purposive sampling was initially used by "seeking out individuals where the processes of being studied are most likely to occur", using appropriate inclusion criteria. ${ }^{22}$ As themes began to emerge, theoretical sampling was deployed by selecting participants who were likely to confirm, clarify and reflect upon themes and issues that emerged from previous interviews. ${ }^{23}$ Snowball sampling was also used by asking participants, speculatively, whether they could recommend or refer new participants to the study from their respective professional networks. ${ }^{24}$ Written informed consent was obtained from all participants.

Data were collected via face-to-face and telephone interviews. A topic guide was devised to aid the interview process and covers questions such as the meaning of the Healthy Prisons Agenda to their work, opportunities and threats to successfully deliver the Agenda, and future strategies that may be useful in ensuring the Agenda is fully embedded in the operations of prisons. All interviews were digitally recorded and transcribed verbatim. They lasted between 21 and 65 minutes. The analysis was undertaken in an iterative cycle. The available data were analysed after each interview and the results informed future data collection. ${ }^{25}$ All transcripts were analysed via NVivo 11 software until data saturation was achieved at 30 interviews, as reflected by the fact that no new themes appeared in the data.

To establish credibility for the research, we triangulated data sources, looking for similarities or dissimilarities between the viewpoints of the participants. ${ }^{26}$ Additionally, a reflexive journal was maintained throughout the research process, ${ }^{27}$ which helped us to remain aware of personal prejudices or biases and to make appropriate changes to the study as we progressed from interview to interview. 


\section{Results}

Several themes emerged as challenges that served to inhibit strategic, managerial and operational staff from implementing the Healthy Prisons Agenda. These tended to emerge as interdependent macro, meso and micro level governance issues, ${ }^{28}$ expressed more specifically in terms of constraints on resources, authoritarianism and operational level resistance to innovation.

\section{Constraints on resources}

Interestingly, participants in operational, managerial and strategic roles, based inside and outside prisons, were unanimously of the view that erosion of resources had resulted directly from the fiscal austerity measures of central government, which they perceived to have had a direct impact on prison health services and to have impeded realisation of the Healthy Prisons Agenda. Reduced prison staffing levels were recognised as a crucial element, especially of operational staff responsible for the dayto-day running of prisons. This was consistent with a $£ 900$ million reduction in the budget for the HMPPS between 2011 and 2017 and a shortfall of operational prison staff. ${ }^{11,29}$ As one prison governor commented:

In my prison, the prison officer-to-prisoner ratio was increased to 1-to-30. So one prison officer ... supervising 30 prisoners. It would be in the newspaper [if teacher-student ratios were this low]... [and] if you replace 30 children with 30 prisoners who are using drugs and have mental health issues...it's very difficult to do [anything]. (Participant 22)

A Prison Service Manager also said:

[The government] introduced the voluntary early departure scheme, where we lost a massive proportion of mature prison staff, which left huge staffing shortages across the prison estate. [The HMPPS is] struggling now with recruitment and retention of staff... [Although] they've taken on thousands of new officers, a massive percentage don't last beyond the first six months so there's a constant recruitment drive. (Participant 15) 
This perspective is consistent with an HMPPS report that $24 \%$ of prison officers have two years or less of experience, and the proportion of experienced staff is declining. ${ }^{30}$ Such a situation invariably affects staff recruitment as well as retention. One participant, employed in an external strategic role (participant 1), described working in the Prison Service as a "marmite job" - 'you either love it or you hate it'; the implication was that a career in the Prison Service lacked appeal for many people, and thereby reinforced the recruitment crisis. A head of service at a prison watchdog (participant 3) moreover remarked that some prisons were paying less than McDonald's, which made recruitment of new staff almost impossible. Operational staff and governors concurred that the contraction of the workforce had required them to focus on urgent matters at all times, such that the Healthy Prisons Agenda seemed discretionary at best.

\section{Authoritarianism}

Some participants perceived that some prison governors exercised an authoritarian managerial style that impeded innovations they viewed to fall beyond the core business of the prison. Participants not directly employed by the Prison Service or an equivalent private provider, for example those working for the NHS, local authorities or voluntary organisations, felt that prison governors commonly created an artificial boundary they were required to respect that represented the frontier of the governors' managerial domain. Territoriality can therefore impede collaboration and partnership working, which external service providers, commissioners and managers described an incessant struggle to persuade governors to embrace health as an integral priority for prisons. One Commissioning Lead for NHS England said:

We ask nicely and we try to negotiate and all ... "Come on, let's have a go." But, fundamentally, I can't say to a governor, "You will ensure that these patients are seen." I can't do it. (Participant 1)

Similarly, participants employed outside prisons believed that central government did not provide sufficient strategic guidance to prompt prison governors and operational prison staff to promote the Healthy Prisons Agenda. Another NHS England Lead observed, "there are 116 prisons and not all governors will understand what is being 
asked of them" (Participant 16), suggesting that refreshed guidance on the imperatives for prison health is needed.

On the other hand, participants based within prisons argued that top-down control from central government thwarted their ability to embrace the Healthy Prisons Agenda. Some prison governors claimed that central government determined their operating procedures and that this interference therefore made it difficult for them to embrace the Agenda:

[Y]ou get a budget, you're told what to spend it on, you're told how many staff you need, you're told what your core day looks like. If [we deviate from this procedure] then [we] get beaten up for it. (Participant 22, a Prison Governor)

In other words, insiders felt that prison governors were not powerful enough, which contrasts with the perspectives of externally based participants.

Operational level resistance to innovation

Whilst prison governors would promote the Healthy Prisons Agenda if only central government would let them, prison staff seemed oblivious to that fact. They displayed scepticism and resistance towards the Agenda. Their narratives suggested that both governors and frontline operational staff often used concerns about security as an excuse to subordinate the Agenda:

[I]t may be in the best interest[s] that prisoners are able to go run around in the yard for an hour a day, but actually security might override and the Prison Officers might say, "Well, we can't do that."... [I]n that sense, prison staff might reduce security as the [convenient excuse]. (Participant 11, Prison Advocacy Lead)

This perspective suggests a widespread prevalence of a command-and-control ethos in English prisons that is underpinned by a prevailing security culture that dismisses prison-based health-promoting activities. Health in prison is portrayed as a utopian oxymoron, inferior to the punitive aims of prison. 
Prison-based participants, by contrast, rationalised this resistance from the perspective of practicality. Their attitude towards the national Smoke-free Prisons Agenda, a blanket ban on smoking in English prisons implemented in 2017, reflected this:

A number of prison staff openly said that they would turn a blind eye to prisoners who smoked. The reason for that was sometimes practical - they didn't have the time or resources to address that because they were dealing with more pressing issues, in their view. (Participant 12, a former Probation Officer)

Participant 19, a Probation Lead, conceded that the systems approach that underpins the focus of the Healthy Prisons Agenda would have to bow to security requirements:

So there's a bit of give and take in that process; we won't get to the end point which is rehabilitation. It's got to be rehabilitation, but we can never lose sight of public protection. (Participant 19)

A Health and Justice Lead described the need for education of prison staff to support the Agenda:

...[As] they don't have that experience in health, you have to teach them to be able to reach the population that you're trying to reach. (Participant 26)

These comments suggest that it is crucial to help prison staff appreciate the fact that the Healthy Prisons Agenda need not undermine public protection, and that implementing the Agenda could indeed benefit the health of the prison workforce, and bring wider benefits in terms of managing complex needs, more effective offender management and more sustainable measures to reduce reoffending. 


\section{Discussion}

This research demonstrates the existence of sectoral, institutional, and occupational barriers that inhibit prison governors and staff from implementing the Healthy Prisons Agenda in English prisons. At the macro-level, these participants reasoned that the current sectoral volatility resulted from the reduction in penal resources, which is not conducive to the implementation of the Agenda in English prisons. Considering that prisons is a setting capturing one of the most marginalised and excluded groups of the society who do not usually present to the NHS, and the one where their health and social care issues can be attended to, ${ }^{7}$ this is obviously a missed opportunity. Furthermore, in a resource-restricted environment, it is easier to default health and wellbeing responsibilities to healthcare staff and, by doing so, to abandon a holistic approach to prisoners' needs. ${ }^{7}$ While the existing literature emphasises the vulnerability of prison staff when resources are limited, ${ }^{11-13}$ our research provides greater insights into prison-workforce planning. Recruitment is very difficult, given the frequently reported unsafe working conditions and unfavourable employment terms. ${ }^{13}$ Whilst the full impact of the government's fiscal austerity measures is not yet apparent, ${ }^{31}$ this finding illuminates the tension between aspirations to promote health within prisons and the reality of institutional instability, which arises from limited resources.. In this context, dedication of more resources to this sector, along with the policy recognition of the cross-governmental cooperation via the National Partnership Agreement 2018-2021, ${ }^{10}$ may restore the current regime of prisons to equilibrium and make this environment more conducive for the Healthy Prisons Agenda.

Moreover, this research highlights that there is a continuum of perceptions regarding prison governors' prerogative. Participants who were not directly accountable to prison governors believed that the governors created a professional silo that impeded a systems approach to facilitating effective prison health policy and practice. Apparently conflicting perspectives of internally and externally located participants over the relative importance of health and security aligns with existing literature. ${ }^{18,19} \mathrm{By}$ contrast, prison governors articulated that central government instructions made it difficult for them to implement the Healthy Prisons Agenda, consistent with other research that has reported that prison governors do not know what is expected of them 
regarding prisoner health. ${ }^{20} \mathrm{~A}$ new policy document, which encapsulates these expectations and promotes collaborative work to break down such insular mentality, may ensure greater longevity of the Agenda.

Finally, this study has highlighted the disparities in perspectives on the challenges prison staff encounter in embracing the Healthy Prisons Agenda. For those who operated outside the prison structure, prison officers were seen as underplaying the value of rehabilitation and overplaying the need for security, consistent with existing studies that have revealed a micromanagement culture that can be detrimental to the Agenda. ${ }^{9,13-16}$ By contrast, this research further suggests that internal prison staff view it as pragmatic not to care about prisoners' health, and that security should always take precedence over rehabilitation. Regardless of this inherent contradiction, there is a consensus that England's penal system urgently needs education and training that will prepare prison officers for the increasingly complex health and welfare needs of the prison population. ${ }^{1-4,17}$ Furthermore, in recognition of the whole-prison approach, the spirits and intendment of the Healthy Prisons Agenda should be embedded within the national, regional, and local prison workforce policy, as well as get implemented via relevant actions concerning line management, appraisal, continuing professional development (CPD) trainings, code of conduct, and overall hierarchy of prison command. Such participatory approach would recognise prison governors and staff as part of the solutions that could ensure the integration of health and care into the prison officers' ethos, as well as into their day-to-day interactions with prisoners. Ultimately, such as approach would also help nurture a rehabilitation-focused culture within the prisons in England. 


\section{Strengths and weaknesses of this study}

This study contextualised the systemic, institutional, and professional blockages prison governors and staff face in implementing the Healthy Prisons Agenda in England. Despite this strength, only 30 key stakeholders in the field of English prisons were interviewed. The study did not consider prisoners' experiences, which future research might address.

The present findings are most relevant to a small number of European countries where a national health ministry commissions prison healthcare, including France, Italy, Norway, Sweden, and Finland. ${ }^{32}$ Future studies may benefit from investigating the barriers prison stakeholders face in embracing the WHO's Healthy Prisons Agenda, particularly in countries where the justice or interior ministry provides healthcare to prisoners, which would allow for transcontinental assessments.

\section{Conclusion}

This paper has argued that a lack of resources at the sectoral level, the conflicting perceptions regarding prison governors' discretion and the need to abide by standard operating procedures at the institutional level, and the ongoing dynamic between security and rehabilitation, are perceived to inhibit the implementation of the Healthy Prisons Agenda in England. The sustainability of the Agenda may be improved by ensuring greater investment, reinvigorating expectations regarding the Agenda, reinforcing the whole-system approach in delivering the Agenda, and providing better training for prison officers. Such concerted efforts should ensure that we embrace prisons as an institution that can be rehabilitative, whilst reinforcing our ongoing pledge to protecting and enhancing the health of the marginalised people confined within them. 


\section{Author statements}

Acknowledgements

The authors thank all the study participants, without whom this research would not have been possible.

\section{Ethical approval}

The study was approved by the University of the West of England Ethics Committee (approval number R1261).

\section{Funding}

This research did not receive any specific grant from funding agencies in the public, commercial, or not-for-profit sectors.

\section{Competing interests}

None declared. 


\section{References}

1. Public Health England. Health and justice needs assessment template: adult prisons-part 2 of the health and justice health needs assessment toolkit for prescribed places of detention, https://www.gov.uk/government/uploads/system/uploads/attachment data/file/ 331628/Health Needs Assessment Toolkit for Prescribed Places of Dete ntion Part 2.pdf; 2014 [accessed 2 March 2018].

2. Fraser A, Gatherer A, Hayton P. Mental health in prisons: great difficulties but are there opportunities? Public Health 2009;123:410-4.

3. Rutherford M, Duggan S. Meeting complex health needs in prisons. Public Health 2009;123:415-8.

4. Stürup-Toft S, O’Moore EJ, Plugge EH. Looking behind the bars: emerging health issues for people in prison. Br Med Bull 2018;1-9.

5. World Health Organization. Health in prisons: health promotion in the prison setting. Summary report on a WHO meeting, http://apps.who.int/iris/bitstream/10665/107506/1/EUR ICP ADA 043\%28S\% 29.pdf; 1995 [accessed 2 March 2018].

6. World Health Organization. Constitution of the World Health Organization, http://apps.who.int/gb/bd/PDF/bd47/EN/constitution-en.pdf?ua=1; 1948 [accessed 22 May 2018].

7. World Health Organization. Prisons and health, http://www.euro.who.int/ data/assets/pdf file/0005/249188/Prisons-andHealth.pdf; 2014 [accessed 22 May 2018].

8. HM Inspectorate of Prisons. Expectations: criteria for assessing the treatment of prisoners and conditions in prisons, http://www.justiceinspectorates.gov.uk/prisons/wpcontent/uploads/sites/4/2014/02/adult-expectations-2012.pdf; 2012 [accessed 2 March 2018].

9. Goffman E. Asylums: essays on the social situation of mental patients and other inmates. Harmondsworth: Penguin; 1961.

10. Ministry of Justice. National partnership agreement for prison healthcare in England 2018 - 2021, https://assets.publishing.service.gov.uk/government/uploads/system/uploads/ 
attachment data/file/697130/moj-national-health-partnership-2018-2021.pdf;

2018 [accessed 22 May 2018].

11. National Audit Office. Mental health in prisons, https://www.nao.org.uk/wpcontent/uploads/2017/06/Mental-health-in-prisons.pdf; 2017 [accessed 2 March 2018].

12. Ministry of Justice. Population and capacity briefing for Friday 31st March 2017,

https://www.gov.uk/government/uploads/system/uploads/attachment data/file/ 605054/prison-population-31-march-2017.xls; 2017 [accessed 2 March 2018].

13. Arnold H. The prison officer. In: Jewkes Y, Crewe B, Bennett J, editors. Handbook on prisons, Oxford: Routledge; 2016, p. 264-83.

14. Dixey R, Woodall, J. Prison staff and the health promoting prison. Int J Prison Health $2011 ; 7: 8-16$.

15. de Viggiani N. Unhealthy prisons: exploring structural determinants of prison health. Sociol Health IIIn 2007;29:115-35.

16. Arnold $\mathrm{H}$. The experience of prison officer training. In: Bennett J, Crewe B, Wahidin A, editors. Understanding prison staff, Cullompton: Willan Publishing; 2008, p. 399-418.

17. Woodall J. Health promoting prisons: an overview and critique of the concept. Prison Service J 2012;202:6-11.

18. Ministry of Justice. Breaking the cycle: effective punishment, rehabilitation and sentencing of offenders,

http://webarchive.nationalarchives.gov.uk/20111114164935/http://www.justice .gov.uk/downloads/consultations/breaking-the-cycle.pdf; 2010 [accessed 2 March 2018].

19. Gojkovic D. Factors influencing the organization of prison mental health services: a cross-national study. Deutschland: Lambert Academic Publishing; 2010.

20. Bryans S. Prison governors: managing prisons in a time of change. Oxford: Routledge; 2012.

21. Strauss AL, Corbin JM. Basics of qualitative research: techniques and procedures for developing grounded theory. California: Sage Publications; 1998. 
22. Denzin NK, Lincoln YS. Handbook of qualitative research. London: Sage Publications; 1994.

23. Mason J. Qualitative researching. California: Sage Publications; 1996.

24. Patton MQ. Qualitative research and evaluation methods. 3rd ed. California: Sage Publications; 2002.

25. Pope C, Ziebland S, Mays N. Qualitative research in health care: analysing qualitative data. BMJ 2000;320:114-6.

26. Shenton AK. Strategies for ensuring trustworthiness in qualitative research projects. Education for Information 2004;22:63-75.

27. Finlay L. "Outing" the researcher: the provenance, process, and practice of reflexivity. Qualitative Health Research 2002;12:531-45.

28. Hudson J, Lowe S. Understanding the policy process: analysing welfare policy and practice. Bristol: The Policy Press; 2004.

29. National Offender Management Service. Annual report and accounts 20152016, https://www.gov.uk/government/publications/noms-annual-report-andaccounts-2015-2016; 2016 [accessed 2 March 2018].

30. Ministry of Justice. National Offender Management Service workforce statistics: March 2017, https://www.gov.uk/government/statistics/nationaloffender-management-service-workforce-quarterly-march-2017; 2017 [accessed 2 March 2018].

31. Ismail N, de Viggiani N. Should we use a direct regulation to implement the Healthy Prisons Agenda in England? A qualitative study among prison key policy makers. J Public Health [Preprint]. 2017 doi:

https://doi.org/10.1093/pubmed/fdx116.

32. Public Health England. Health \& justice annual review 2015/16, https://www.gov.uk/government/uploads/system/uploads/attachment data/file/ 565232/health and justice annual review 2015 to 2016.pdf; 2016 [accessed 2 March 2018]. 